\title{
Article \\ Sex Differences in the Oxygenation of the Left and Right Prefrontal Cortex during Moderate-Intensity Exercise
}

\author{
Yuta Inagaki ${ }^{1,2, *(\mathbb{D})}$, Reo Sato ${ }^{1}$, Takashi Uchiyama ${ }^{1}$, Sho Kojima ${ }^{1}$, Shinichiro Morishita ${ }^{1,3,4}$, Weixiang Qin ${ }^{3,4}$ \\ and Atsuhiro Tsubaki $1,3,4$ (D) \\ 1 Department of Physical Therapy, Niigata University of Health and Welfare, Niigata 950-3198, Japan; \\ hpa14046@nuhw.ac.jp (R.S.); hpa14012@nuhw.ac.jp (T.U.); hpa14034@nuhw.ac.jp (S.K.); \\ morishita@nuhw.ac.jp (S.M.); tsubaki@nuhw.ac.jp (A.T.) \\ 2 Department of Rehabilitation, Kobe City Medical Center General Hospital, Kobe-city 650-0047, Japan \\ 3 Institute for Human Movement and Medical Sciences, Niigata University of Health and Welfare, \\ Niigata 950-3198, Japan; hpm17005@nuhw.ac.jp \\ 4 Graduate School of Health and Welfare, Niigata University of Health and Welfare, Niigata 950-3198, Japan \\ * Correspondence: hpa14011@nuhw.ac.jp
}

Citation: Inagaki, Y.; Sato, R.; Uchiyama, T.; Kojima, S.; Morishita, S.; Qin, W.; Tsubaki, A. Sex Differences in the Oxygenation of the Left and Right Prefrontal Cortex during Moderate-Intensity Exercise. Int. J. Environ. Res. Public Health 2021, 18, 5212. https://doi.org/10.3390/ ijerph18105212

Academic Editors: Fabrizio Perroni, Elena Cavarretta, Erica Gobbi, Pantelis Nikolaidis and Juan Del Coso

Received: 18 March 2021

Accepted: 11 May 2021

Published: 14 May 2021

Publisher's Note: MDPI stays neutral with regard to jurisdictional claims in published maps and institutional affiliations.

Copyright: (c) 2021 by the authors. Licensee MDPI, Basel, Switzerland. This article is an open access article distributed under the terms and conditions of the Creative Commons Attribution (CC BY) license (https:// creativecommons.org/licenses/by/ $4.0 /)$

\begin{abstract}
Introduction: Differences in cognitive performance with exercise between men and women have previously been reported. In this study, we evaluated between-sex differences in oxygenation of the prefrontal cortex (PFC) with moderate-intensity aerobic exercise (AE), which could contribute to noted differences in cognitive function. Method: The subjects were ten men (age, $21.5 \pm 0.5$ years; height, $171.7 \pm 4.8 \mathrm{~cm}$; weight, $65.6 \pm 5.6 \mathrm{~kg}$ ) and ten women (age, $21.4 \pm 0.5$ years; height, $157.6 \pm 4.9 \mathrm{~cm}$; weight, $51.3 \pm 6.5 \mathrm{~kg}$ ). They completed our AE protocol, consisting of a 30 -min leg-ergometer cycling at an intensity of 50\% peak oxygen uptake, with an initial 4-min rest period for baseline measurement. Measures of the dynamics of cerebral oxygenation included: oxygenated hemoglobin $(\mathrm{O} 2 \mathrm{Hb})$ in the left and right PFC (LR-PFC) and deoxygenated hemoglobin $(\mathrm{HHb})$. The 30-min exercise period was subdivided into six 5-min phases, with the average and peak values determined in each phase. Results: A significant interaction was found between LR-PFC $\mathrm{HHb}$ and sex $(p<0.001)$, with significantly higher values in men than in women in phases 3-6 $(p<0.05)$. Conclusion: We report a significant sex effect of $\mathrm{HHb}$ in the LR-PFC.
\end{abstract}

Keywords: prefrontal cortex; oxygenated hemoglobin; deoxygenated hemoglobin; sex differences; aerobic exercise

\section{Introduction}

Currently, medical practice provides appropriate treatment, rehabilitation, and exercise prescription to patients with a variety of diseases. One of the major interventions is aerobic exercise (AE). AE contributes to the maintenance and improvement of cardiopulmonary function, with $\geq 30$-min of $\mathrm{AE}$, performed at an intensity of $40-60 \%$ of peak oxygen uptake (peakVO $\mathrm{V}_{2}$ ), being effective to improve physical activity levels [1]. It has been reported that regular $\mathrm{AE}$ can reduce body mass index (BMI) and lower resting heart rate among obese individuals [2,3]. In addition, $\mathrm{AE}$ is effective in reducing the prevalence of obesity [4]. Thus, AE is used for health promotion and anti-obesity treatment. Of note, moderate acute exercise improves not only physical function but also cognitive function through an increase in cerebral blood flow to the prefrontal cortex (PFC), which has been identified in both young and elderly individuals [5-10]. Based on current evidence, increased PFC oxygenation during AE has been shown to enhance physical and cognitive function. In addition, it has been clarified that the implementation of acute aerobic exercise for young men and women promotes induced neuroplasticity of the primary motor cortex and corticospinal pathway regardless of the difference in hormones between men and women [11]. Endocrine function associated with AE underpins improvements in adaptations to exercise and to improvement in cognitive and physical function, including optimal 
body composition $[12,13]$. However, unlike age, sex does not seem to be consistently taken into account for $\mathrm{AE}$ prescription. According to previous studies, testosterone is involved in muscle hypertrophy and improved performance with resistance exercise [14,15]. Increases in testosterone levels have also been reported after moderate-intensity AE [16-18]. In addition, testosterone has been reported to be involved in suppressing the onset of lifestyle-related diseases, such as diabetes [19], and low levels of testosterone are associated with more atherosclerosis, coronary artery disease, and cardiovascular events [20-22]. The effects of testosterone on increases in muscle strength have previously been reported, such as higher knee flexion and extension muscle strength, normalized to the proportion of thigh muscles, in men than in women [23]. However, interpretation of acute changes with $\mathrm{AE}$ are more difficult to interpret, due to significant changes in estrogen levels during the menstrual cycle, although some studies have reported increased estrogen levels with exercise $[24,25]$. Increases in estrogen levels have been associated to muscle protection during resistance exercise [26], as well as lower impedance to microcirculation in the brain and increases the blood flow in the internal carotid artery system [27]. Estrogen receptors are localized on vascular endothelial cells and vascular smooth muscle cells, causing a vasodilation response, an increase in cerebral blood flow in the cerebrum and cerebellum, and maintenance or improvement of cognitive function [28-30]. The improvements in cognitive function with $\mathrm{AE}$ are sex-specific, with a higher correct answer rate to visual tasks for men and to language tasks for women [31]. There may also be an age-specific effect, with a significant delay in blood flow in the region of the middle cerebral artery during mediumintensity AE having been reported in older women, compared to younger women [32]. A further study highlighted the sex-specific effect, regardless of age, with differences in cerebral perfusion pressure during exercise between younger men and women [33]. A previous study evaluating sex differences in the PFC demonstrated a significantly higher level of PFC oxygenation in men than in women during cognitive tasks [34]. However, other studies have reported that women were found to have greater cerebral oxygenation levels during cognitive tasks $[35,36]$. There are also reports that no significant differences were found between the sexes in this aspect [37]. This shows a discrepancy in current evidence regarding sex-based difference the oxygenation of the PFC during cognitive tasks. Despite knowledge of these sex differences for exercise prescription, the effects of AE on PFC oxygenation are inconsistent.

Near infrared spectroscopy (NIRS) provides the technology to measure the oxygen dynamics in the cerebral cortex during AE. NIRS measures the change in the concentration of oxygenated hemoglobin $\left(\mathrm{O}_{2} \mathrm{Hb}\right)$ and deoxygenated hemoglobin $(\mathrm{HHb})$ caused by cerebral blood flow responses, coupled with nerve activity [38], with an increase in $\mathrm{O}_{2} \mathrm{Hb}$ reflecting an increase in the nerve activity in brain parenchyma [39]. NIRS measurements are robust, providing reliable measures even during unrestrained activities, such as running and leg-cycle ergometer pedaling [40,41]. As such, the purpose of our study was to investigate sex-specific differences in PFC oxygenation during moderate-intensity AE. In this study, we hypothesized that left and right $\mathrm{PFC}_{2} \mathrm{Hb}$ showed a significantly greater increase with exercise in women than in men.

\section{Materials and Methods}

The relevant schematic representation of the study procedures and characteristics of our study population are shown in Figure 1 and Table 1. We enrolled 20 young adults, in their 20s (men, $21.5 \pm 0.5$ years; women, $21.4 \pm 0.5$ years), with no significant past medical history. The Edinburgh Handedness Inventory was used to determine dominance, with only right-handed individuals included in our study group. None of the participants enrolled had been habitually exercising over the previous 6 months. Participants were screened to exclude a history of respiratory, circulatory, and neurological diseases. 


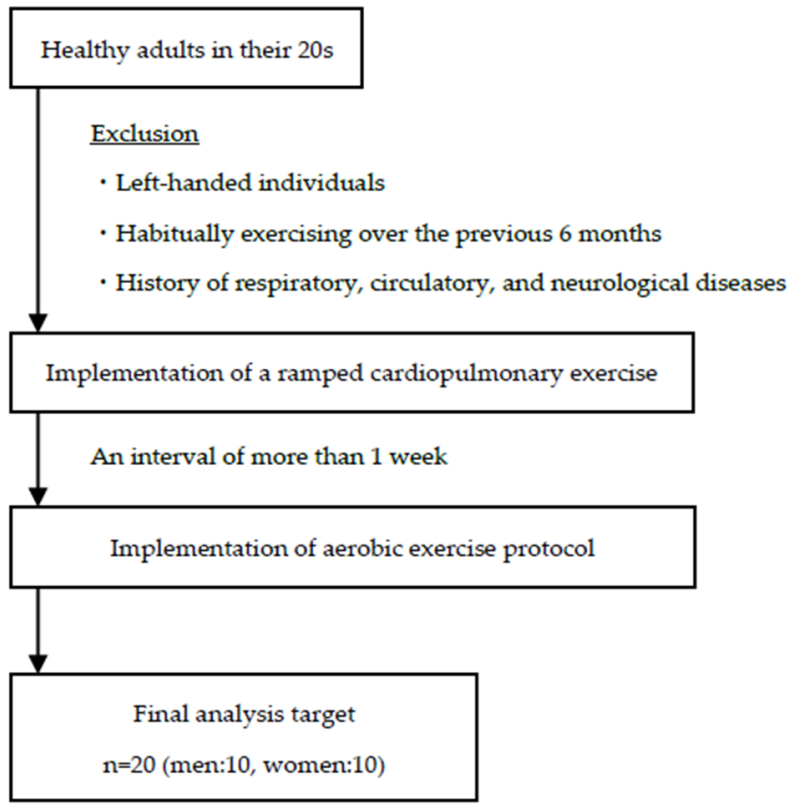

Figure 1. A schematic representation of the study procedures.

Table 1. Participants' characteristics.

\begin{tabular}{cccc}
\hline & Men $(\boldsymbol{n}=\mathbf{1 0})$ & Women $(\boldsymbol{n}=\mathbf{1 0})$ & $p$-Value \\
\hline Age & $21.5 \pm 0.5(0.02)$ & $21.4 \pm 0.5(0.02)$ & $p=0.67$ \\
Height $(\mathrm{cm})$ & $171.7 \pm 4.8(0.03)$ & $157.6 \pm 4.9(0.03)$ & $p<0.001$ \\
Weight $(\mathrm{kg})$ & $65.6 \pm 5.6(0.09)$ & $51.3 \pm 6.5(0.13)$ & $p<0.001$ \\
Peak VO $(\mathrm{mL} / \mathrm{min} / \mathrm{kg})$ & $1859.6 \pm 244.5(0.13)$ & $1143.9 \pm 351.0(0.31)$ & $p<0.001$ \\
Peak load (watt) & $189.7 \pm 28.3(0.15)$ & $119.4 \pm 19.0(0.16)$ & $p<0.001$ \\
$50 \%$ load (watt) & $87.0 \pm 16.0(0.18)$ & $48.8 \pm 10.7(0.22)$ & $p<0.001$ \\
\hline
\end{tabular}

Average \pm standard error, ( ): CV range.

Our study was approved by the ethics committee of Niigata University of Health and Welfare (approval number: 17770-170106) and was conducted in accordance with the tenets of the Declaration of Helsinki.

A ramped cardiopulmonary exercise protocol was used to determine the peak $\mathrm{VO}_{2}$ for each participant, as previously described [42,43]. Briefly, the protocol consisted of a $4 \mathrm{~min}$ rest, followed by a $4 \mathrm{~min}$ warm-up, the ramped cardiopulmonary protocol, and a $2 \mathrm{~min}$ cool-down. For the ramped protocol, the workload was increased in workload increments workload of $20 \mathrm{~W} / \mathrm{min}$, using stationary bicycle (Aerobike 75XLIII; Konami, Tokyo, Japan). To measure the $\mathrm{VO}_{2}$, an exhaled gas analyzer was used (AE-310S; Minato Medical Science, Osaka, Japan). Exhaustion was defined as follows [44] (1): a plateau $\mathrm{VO}_{2} ;(2)$ a respiratory exchange ratio $>1.1$; (3) HR values near the age-predicted maximal heart rate, calculated as $220-(0.65 \times$ age $)$; and (4) a decrease in the cycling cadence to $<50 \mathrm{rpm}$, despite strong verbal encouragement. The highest value $\mathrm{VO}_{2}$ obtained was considered as the peak $\mathrm{VO}_{2}$. Additionally, we determined anaerobic thresholds (ATs) using the V-slope method during the ramped protocol, as previously described [45].

The aerobic exercise protocol is shown in Figure 2. To measure PFC oxygenation in all participants, a leg-cycle ergometer was used for $\mathrm{AE}$, at a constant load of $50 \%$ of the measured peak $\mathrm{VO}_{2}$ for each participant for a duration of $30 \mathrm{~min}$, which was deemed to be a moderate-intensity level of AE. A schematic of the experimental protocol is provided in Figure 1. The session consisted of an initial 4-min resting period, with the subsequent AE period subdivided into six 5-min phases, during which participants were verbally encouraged to maintain a pedaling rate of 55-60 revolutions per min. To prevent movement artefacts on measurements, participants were instructed to not move their head or trunk and to not talk during measurements. 


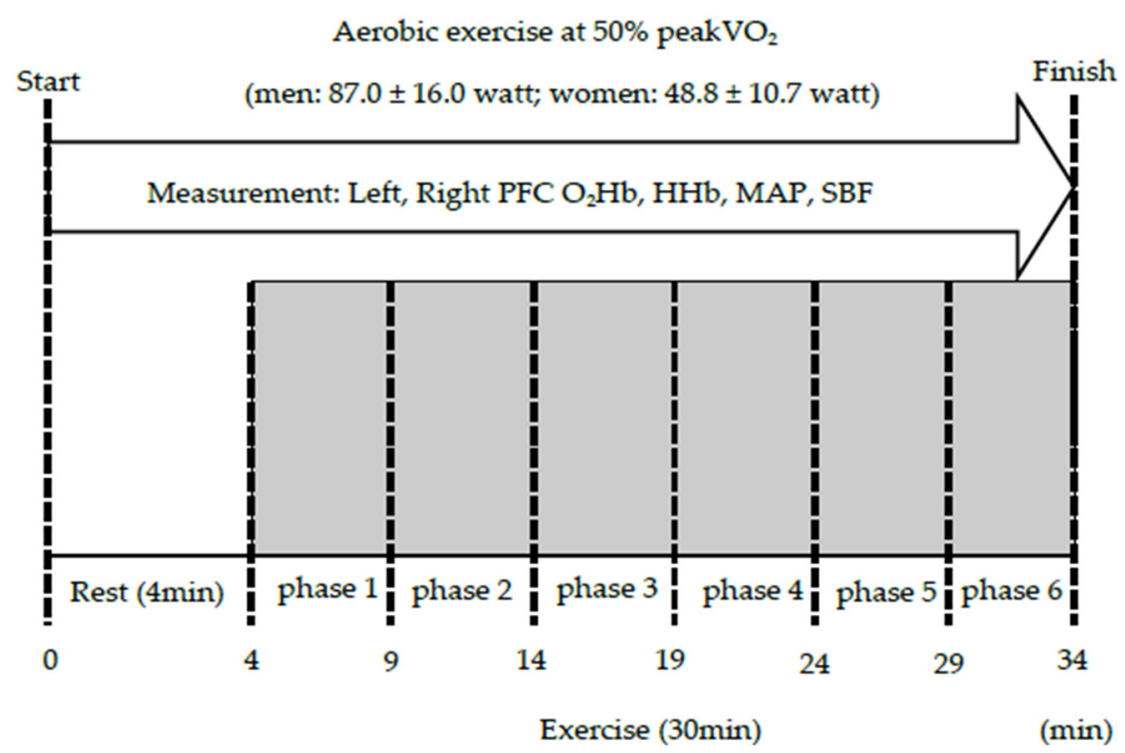

Figure 2. Experiment protocol. PFC: Prefrontal cortex, $\mathrm{O}_{2} \mathrm{Hb}$ : oxygenated hemoglobin, $\mathrm{HHb}$ : deoxygenated hemoglobin; MAP: Mean arterial pressure, SBF: Scalp blood flow.

A brain oxygen monitor (OMM-3000/16, Shimadzu Corporation) was used for the measurement of the dynamics of cerebral oxygenation. The following variables were measured at baseline and during each of the six phases of the AE protocol: $\mathrm{O}_{2} \mathrm{Hb}$ of the left and right PFC; $\mathrm{HHb}$ of the left and right PFC; mean arterial pressure (MAP); and scalp blood flow (SBF). According to the international 10-20 system, the head holder was set along the Fz position, which was located at three-tenths of the distance from the glabella to the external occipital protuberance. Ten source fiber and ten detector fiber were applied in a $5 \times 4$ array of 5 , and PFC oxygenation was measured using all 31 channels. The fiber spacing was set at $30 \mathrm{~mm}$, with a sampling rate of $160 \mathrm{~ms}$. Recording from the region of interest was captured as follows; channels 1, 4, 5, and 8 for the left PFC, and channels 3, 6, 7, and 10 for the right $\mathrm{PFC}$ (Figure 3). $\mathrm{O}_{2} \mathrm{Hb}$ and $\mathrm{HHb}$ data were averaged at each channel, and a $0.1-\mathrm{Hz}$ low pass filter was used to decrease noise from the heartbeat $[46,47]$. As previously described [48,49], cerebral hemoglobin concentration was measured using three differential continuous waves $(780 \mathrm{~nm}, 804 \mathrm{~nm}$, and $830 \mathrm{~nm})$, based on the Modified Beer-Lambert Law [50], with absorbance at the start of measurement was defined as the initial absorbance of each wavelength. As it was not possible to measure the differential path-lengths using the continuous-wave NIRS system, absorbance was assumed to be a constant, with changes in the hemoglobin signal denoted in arbitrary units $(\mathrm{mM} \cdot \mathrm{cm})[51,52]$.

A previous study indicated that $\mathrm{O}_{2} \mathrm{Hb}$ is likely to be affected by the MAP and SBF [53]. Therefore, these latter two variables were also measured. MAP was measured using a Finometer (Finapres Medical Systems, Amsterdam, The Netherlands) attached to the third finger of the left hand, with SBF measured at the forehead using a laser blood flowmeter (Omegaflo FLO-C1; Omegawave Inc., Tokyo, Japan). MAP and SBF were measured at baseline and during each of the six phases of the AE protocol.

Each measure was calculated as the change in value during each of the six phases of the AE protocol, from baseline measured during the 4-min pre-exercise resting period. To calculate the mean and standard deviation (SD) values over each of the six phases of the AE protocol, each 5-min phase was subdivided into 1-min intervals. Variables were then compared between men and women using a two-way repeated-measures analysis of variance (ANOVA), with the Tukey-Kramer method used as a post-hoc test. The peak (highest) and time to peak value were then determined. Next, we performed a normality test and confirmed homoscedasticity. A student's t-test was used to evaluate betweenphase differences within each sex. All analyses were performed using Excel (Microsoft), 
with the add-in software Statcel 4 (OMS Publishing Inc., Saitama, Japan). A significance level of 0.05 was used for all statistical analyses.

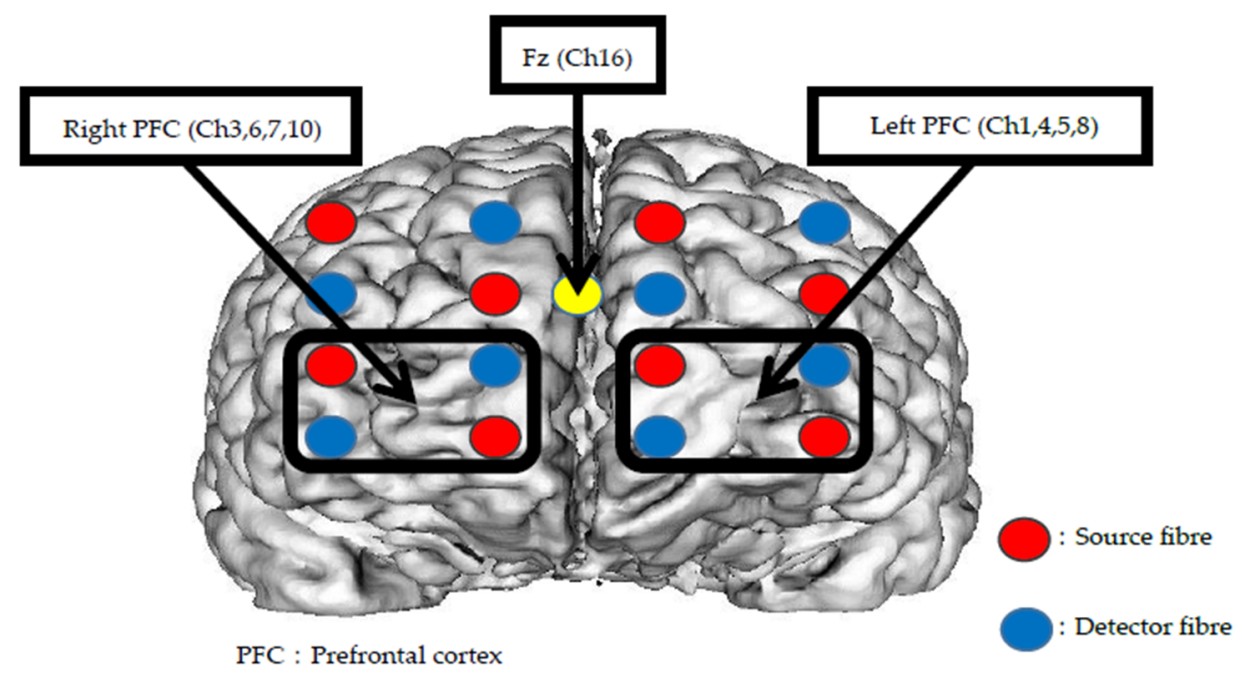

Figure 3. Measurement channels and fiber arrangement.

\section{Results}

\subsection{Changes in the Oxygenation Dynamics of the PFC during Exercise}

\subsubsection{Left and Right PFC Oxygen Dynamics}

The results are shown in Tables 2 and 3. The two-way repeated measures ANOVA for the $\mathrm{O}_{2} \mathrm{Hb}$ of the left PFC revealed a main effect of time $\left(\mathrm{F}_{(6,126)}=15.17, p<0.001\right)$ and $\operatorname{sex}\left(\mathrm{F}_{(1,126)}=28.52, p<0.001\right)$, with no significant time by sex interaction $\left(\mathrm{F}_{(6,126)}=1.83\right.$, $p=0.097)$. Similarly for the right PFC, we identified a main effect of time $\left(\mathrm{F}_{(6,126)}=17.97\right.$, $p<0.001)$ and $\operatorname{sex}\left(\mathrm{F}_{(1,126)}=25.05, p<0.001\right)$, with no significant time by sex interaction $\left(\mathrm{F}_{(6,126)}=1.40, p=0.21\right)$. For $\mathrm{HHb}$, for the left PFC, we identified a main effect time $\left(\mathrm{F}_{(6,126)}=8.67, p<0.001\right)$ and $\operatorname{sex}\left(\mathrm{F}_{(1,126)}=37.80, p<0.001\right)$, as well as a time by sex interaction $\left(\mathrm{F}_{(6,126)}=6.49, p<0.001\right)$. The post-hoc analysis identified a significantly higher $\mathrm{HHb}$ value in phases $3-6$ in men than in women $(p<0.05)$. In fact, for phase $4-6$, a significant increase in $\mathrm{HHb}$, compared to baseline, was only identified in men $(p<0.05)$. The findings were comparable for the right PFC, with a main effect of time $\left(\mathrm{F}_{(6,126)}=10.10\right.$, $p<0.001)$ and condition $\left(\mathrm{F}_{(1,126)}=28.29, p<0.001\right)$ on $\mathrm{HHb}$, as well as a time by condition interaction $\left(\mathrm{F}_{(6,126)}=3.48, p=0.003\right)$. Again, on post-hoc analysis, $\mathrm{HHb}$ values were significantly greater in men than in women for phase 3-6 of the exercise protocol $(p<0.05)$. However, in the right PFC, while only men showed an increase in $\mathrm{HHb}$ level, compared to baseline, in phase 4-6 $(p<0.01)$, women also did show a significantly higher $\mathrm{HHb}$ level in phases $5-6$, compared to baseline $(p<0.05)$.

\subsubsection{Changes in the MAP and SBF during Exercise}

The results are shown in Table 4. MAP was influenced by a main effect of time $\left(\mathrm{F}_{(6,126)}=13.47, p<0.001\right)$ but with no influence of $\operatorname{sex}\left(\mathrm{F}_{(1,126)}=4.64, p=0.033\right)$ or a time by sex interaction $\left(\mathrm{F}_{(6,126)}=19.00, p=0.97\right)$. In contrast, SBF was influenced by a main effect of both time $\left(\mathrm{F}_{(6,126)}=19.00, p<0.001\right)$ and $\operatorname{sex}\left(\mathrm{F}_{(1,126)}=0.11, p<0.74\right)$, without a time by sex interaction $\left(\mathrm{F}_{(6,126)}=0.03, p=0.99\right)$.

\subsection{Comparison of the Peak Time and Peak Value for Each Measure during Exercise}

The results are shown in Table 5. No sex differences were identified for peak time or peak values for any of the measured variables (paired $t$-test). Student's $t$-test analysis revealed significantly higher peak values of $\mathrm{O}_{2} \mathrm{Hb}(p<0.05)$ and $\mathrm{HHb}(p<0.01)$ in men than in women, for both the left and right PFC. No significant between-sex differences in the peak value of MAP and SBF were identified. 
Table 2. Changes in $\mathrm{PFC} \mathrm{O}_{2} \mathrm{Hb}$ during exercise.

\begin{tabular}{|c|c|c|c|c|c|c|c|c|c|c|c|}
\hline & & Rest & Phase 1 & Phase 2 & Phase 3 & Phase 4 & Phase 5 & Phase 6 & Time & Between Sex & Interaction \\
\hline $\begin{array}{c}\text { Left PFC } \\
\mathrm{O}_{2} \mathrm{Hb} \\
(\mathrm{Mm} \cdot \mathrm{cm})\end{array}$ & $\begin{array}{c}\text { men } \\
\text { women }\end{array}$ & $\begin{array}{c}0.00 \pm 0 \\
(0) \\
0.00 \pm 0 \\
(0)\end{array}$ & $\begin{array}{c}0.00 \pm 0.01 \\
(0) \\
-0.01 \pm 0.01 \\
(-1)\end{array}$ & $\begin{array}{c}0.09 \pm 0.02 \\
(0.22) \\
0.04 \pm 0.01 \\
(0.25)\end{array}$ & $\begin{array}{c}0.13 \pm 0.02 \\
(0.15) \\
0.06 \pm 0.02 \\
(0.33)\end{array}$ & $\begin{array}{c}0.14 \pm 0.02 \\
(0.14) \\
0.06 \pm 0.03 \\
(0.5)\end{array}$ & $\begin{array}{c}0.14 \pm 0.02 \\
(0.14) \\
0.07 \pm 0.03 \\
(0.43)\end{array}$ & $\begin{array}{c}0.15 \pm 0.02 \\
(0.13) \\
0.07 \pm 0.03 \\
(0.43)\end{array}$ & $p<0.001$ & $p<0.001$ & $p=0.097$ \\
\hline $\begin{array}{c}\text { Right PFC } \\
\mathrm{O}_{2} \mathrm{Hb} \\
(\mathrm{mM} \cdot \mathrm{cm})\end{array}$ & women & $\begin{array}{c}0.00 \pm 0 \\
(0) \\
0.00 \pm 0 \\
(0)\end{array}$ & $\begin{array}{c}0.00 \pm 0.01 \\
(0) \\
-0.01 \pm 0.01 \\
(-1)\end{array}$ & $\begin{array}{c}0.07 \pm 0.02 \\
(0.29) \\
0.04 \pm 0.01 \\
(0.25)\end{array}$ & $\begin{array}{c}0.11 \pm 0.02 \\
(0.18) \\
0.05 \pm 0.01 \\
(0.2)\end{array}$ & $\begin{array}{c}0.11 \pm 0.02 \\
(0.18) \\
0.06 \pm 0.01 \\
(0.17)\end{array}$ & $\begin{array}{c}0.12 \pm 0.02 \\
(0.17) \\
0.07 \pm 0.01 \\
(0.14)\end{array}$ & $\begin{array}{c}0.12 \pm 0.02 \\
(0.17) \\
0.06 \pm 0.01 \\
(0.17)\end{array}$ & $p<0.001$ & $p<0.001$ & $p=0.21$ \\
\hline
\end{tabular}

Table 3. Changes in PFC HHb during exercise.

\begin{tabular}{|c|c|c|c|c|c|c|c|c|c|c|c|}
\hline & & Rest & Phase 1 & Phase 2 & Phase 3 & Phase 4 & Phase 5 & Phase 6 & Time & Between Sex & Interaction \\
\hline $\begin{array}{c}\text { Left PFC } \\
\mathrm{HHb} \\
(\mathrm{mM} \cdot \mathrm{cm})\end{array}$ & $\begin{array}{c}\text { men } \\
\text { women }\end{array}$ & $\begin{array}{c}0.00 \pm 0 \\
(0) \\
0.00 \pm 0 \\
(0)\end{array}$ & $\begin{array}{c}0.00 \pm 0 \\
(0) \\
0.01 \pm 0 \\
(0)\end{array}$ & $\begin{array}{c}0.01 \pm 0.01 \\
(1) \\
0.01 \pm 0 \\
(0)\end{array}$ & $\begin{array}{c}0.03 \pm 0.01 \dagger \\
(0.33) \\
0.00 \pm 0 \\
(0)\end{array}$ & $\begin{array}{c}0.05 \pm 0.01 *,+ \\
(0.2) \\
0.00 \pm 0 \\
(0)\end{array}$ & $\begin{array}{c}0.07 \pm 0.011^{* *},++ \\
(0.14) \\
0.01 \pm 0.01 \\
(1)\end{array}$ & $\begin{array}{c}0.08 \pm 0.011^{* *}+ \\
(0.13) \\
0.01 \pm 0.01 \\
(1)\end{array}$ & $p<0.001$ & $p<0.001$ & $p<0.001$ \\
\hline
\end{tabular}

Average \pm standard error, ( ): CV range; vs rest $*: p<0.05,{ }^{* *}: p<0.01$ vs women $t: p<0.05,+t: p<0.01$; PFC: Prefrontal cortex, HHb: deoxygenated hemoglobin.

Table 4. Changes in MAP and SBF during exercise, from baseline.

\begin{tabular}{|c|c|c|c|c|c|c|c|c|c|c|c|}
\hline & & Rest & Phase 1 & Phase 2 & Phase 3 & Phase 4 & Phase 5 & Phase 6 & Time & Between Sex & Interaction \\
\hline $\begin{array}{c}\text { MAP } \\
(\mathrm{mmHg})\end{array}$ & $\begin{array}{c}\text { men } \\
\text { women }\end{array}$ & $\begin{array}{c}0.01 \pm 0.02 \\
(2.0) \\
-0.03 \pm 0.06 \\
(-2.0)\end{array}$ & $\begin{array}{c}25.05 \pm 2.51 \\
(0.10) \\
21.68 \pm 2.25 \\
(0.10)\end{array}$ & $\begin{array}{c}25.49 \pm 3.88 \\
(0.15) \\
19.51 \pm 1.64 \\
(0.08)\end{array}$ & $\begin{array}{c}18.73 \pm 4.28 \\
(0.23) \\
14.65 \pm 1.92 \\
(0.13)\end{array}$ & $\begin{array}{c}18.40 \pm 4.22 \\
(0.23) \\
13.78 \pm 2.07 \\
(0.15)\end{array}$ & $\begin{array}{c}17.13 \pm 4.83 \\
(0.28) \\
14.38 \pm 2.44 \\
(0.17)\end{array}$ & $\begin{array}{c}18.71 \pm 3.53 \\
(0.19) \\
15.68 \pm 2.84 \\
(0.18)\end{array}$ & $p<0.001$ & $p=0.033$ & $p=0.97$ \\
\hline $\begin{array}{l}\text { SBF } \\
\text { (a.u.) }\end{array}$ & $\begin{array}{c}\text { men } \\
\text { women }\end{array}$ & $\begin{array}{c}0.01 \pm 0 \\
(0) \\
0.01 \pm 0 \\
(0)\end{array}$ & $\begin{array}{c}0.65 \pm 0.39 \\
(0.6) \\
0.08 \pm 0.17 \\
(2.13)\end{array}$ & $\begin{array}{c}3.74 \pm 0.74 \\
(0.20) \\
3.83 \pm 1.07 \\
(0.28)\end{array}$ & $\begin{array}{c}5.61 \pm 1.02 \\
(0.18) \\
5.32 \pm 1.24 \\
(0.23)\end{array}$ & $\begin{array}{c}6.46 \pm 1.07 \\
(0.17) \\
6.25 \pm 1.28 \\
(0.20)\end{array}$ & $\begin{array}{c}6.98 \pm 1.17 \\
(0.17) \\
7.01 \pm 1.29 \\
(0.18)\end{array}$ & $\begin{array}{c}6.99 \pm 1.27 \\
(0.18) \\
6.74 \pm 1.13 \\
(0.17)\end{array}$ & $p<0.001$ & $p=0.74$ & $p=0.99$ \\
\hline
\end{tabular}

Average \pm standard error, ( ): CV range; MAP: Mean arterial pressure, SBF: Scalp blood flow. 
Table 5. Peak time and peak value of each measure during exercise.

\begin{tabular}{cccc}
\hline & Peak Time (Men) & Peak Time (Women) & $p$-Value \\
\hline Left $\mathrm{PFC}_{2} \mathrm{Hb}$ & $19.7 \pm 2.5(0.13)$ & $17.8 \pm 2.1(0.12)$ & $p=0.56$ \\
Right $\mathrm{PFC} \mathrm{O}_{2} \mathrm{Hb}$ & $17.6 \pm 2.0(0.11)$ & $20.3 \pm 2.5(0.12)$ & $p=0.40$ \\
Left $\mathrm{PFC} \mathrm{HHb}$ & $28.7 \pm 0.5(0.02)$ & $22.8 \pm 2.7(0.12)$ & $p=0.084$ \\
Right $\mathrm{PFC} \mathrm{HHb}$ & $26.7 \pm 1.1(0.04)$ & $24.3 \pm 2.9(0.12)$ & $p=0.45$ \\
$\mathrm{MAP}$ & $6.5 \pm 2.2(0.34)$ & $6.5 \pm 2.4(0.37)$ & $p=1$ \\
$\mathrm{SBF}$ & $22.5 \pm 1.6(0.07)$ & $22.1 \pm 1.9(0.09)$ & $p=0.88$ \\
\hline & Peak Value (Men) & Peak Value (Women) & $p$-Value \\
\hline Left PFC $\mathrm{O}_{2} \mathrm{Hb}$ & $0.17 \pm 0.02(0.12)$ & $0.09 \pm 0.02(0.22)$ & $p=0.017$ \\
Right $\mathrm{PFC} \mathrm{O}_{2} \mathrm{Hb}$ & $0.15 \pm 0.02(0.13)$ & $0.08 \pm 0.01(0.13)$ & $p=0.011$ \\
Left PFC HHb & $0.08 \pm 0.02(0.25)$ & $0.03 \pm 0.01(0.33)$ & $p=0.002$ \\
Right PFC HHb & $0.09 \pm 0.01(0.11)$ & $0.04 \pm 0.01(0.25)$ & $p=0.002$ \\
$\mathrm{MAP}$ & $34.71 \pm 3.52(0.10)$ & $29.98 \pm 2.39(0.08)$ & $p=0.27$ \\
$\mathrm{SBF}$ & $8.14 \pm 1.28(0.16)$ & $8.47 \pm 1.42(0.17)$ & $p=0.86$ \\
\hline
\end{tabular}

Average \pm standard error, ( ): CV range; The unit of peak time is minutes; PFC: Prefrontal cortex, $\mathrm{O}_{2} \mathrm{Hb}$ : oxygenated hemoglobin, $\mathrm{HHb}$ : deoxygenated hemoglobin; MAP: Mean arterial pressure, SBF: Scalp blood flow.

\section{Discussion}

\subsection{Change in Each Measure during Exercise, Compared to the Resting Mean}

The purpose of this study was to investigate sex-specific effects on PFC oxygenation during moderate-intensity AE. We examined this issue by comparing the PFC oxygen dynamics during a leg-cycle ergometer protocol of moderate-intensity AE between men and women. In this study, no condition interaction was observed in $\mathrm{O}_{2} \mathrm{Hb}$ of $\mathrm{PFC}$. $\mathrm{HHb}$ was significantly increased in phases 4-6 in men. It is hard to say that changes in $\mathrm{HHb}$ alone reflect the neural activity. Therefore, we believe that there was no sex difference in the activation of neural activity in PFC in this study. However, a significant increase in $\mathrm{HHb}$ was observed only in men, which may be due to the effect of sex hormones on the vascular system. Exercise has been reported to increase estrogen levels in women [24], with increased estrogen levels reducing the impedance of microcirculation in the brain and increasing the blood flow to the internal carotid artery system [25]. On the other hand, testosterone effects, which are more abundant in men, on the cerebrovascular system are unclear. Therefore, it is possible that sex hormones affect changes in $\mathrm{HHb}$.

In this study, there was no significant change in $\mathrm{PFC}_{2} \mathrm{Hb}$ between men and women, but $\mathrm{HHb}$ was significantly increased in men. We believe this is a novelty in this study, but further studies are needed to consider the effects of sex hormones. In the future, it will be necessary to clarify the cerebral oxygen dynamics during exercise in men and women in consideration of the measurement of sex hormone concentration. We note that we did not identify a main effect of sex on MAP and SBF, indicating that the blood pressure and sweating responses during exercise are similar between men and women and, thus, would not have contributed to measured differences in $\mathrm{O}_{2} \mathrm{Hb}$. It is important to consider, however, a previous study which reported a lower level of sweating among women than men during high-intensity exercise [54]. This exercise intensity specific difference could be explained by the more efficient sweating capacity (defined as the effective sweating/whole body sweating amount $\times 100$ ) in women than in men. An increase in exercise intensity raises the body temperature and, thus, promotes a sweating response [55], as well as an increase in blood flow through the external carotid artery system, both of which increase the sweating response [52]. Therefore, between-sex differences in sweating, and possibly in MAP and SBF, would be expressed at higher levels of AE than we used in our study.

\subsection{Peak Time and Peak Value of Each Measure during Exercise}

We did not identify significant between-sex differences in the peak time of each measure, indicative of a similar underlying pattern of control of measured variables in men and women. Of note was our finding that peak values of oxygenation in the left and right 
PFC occurred at about $20 \mathrm{~min}$ of exercise, indicating that about $20 \mathrm{~min}$ of moderate-intensity $\mathrm{AE}$ is necessary to derive benefits, regardless of sex. However, considering our findings of higher peak $\mathrm{O}_{2} \mathrm{Hb}$ and peak $\mathrm{HHb}$ values in men than in women, moderate-intensity $\mathrm{AE}$ may be a more effective stimulus in men than in women.

\subsection{Limitations of This Study}

This study demonstrated sex-related differences in the response of oxygen dynamics to the left and right PFC to moderate-intensity AE. However, we did not clarify the actual effects of sex differences in oxygenation on cognitive function and sex hormone during AE. Moreover, our study group consisted of healthy young adults. In the future, it will be necessary to investigate changes in PFC during AE in the elderly, taking sex hormone into consideration. Moreover, in this study, potentially confounding factors were not included in our analysis. In the future, it will be necessary to collect sufficient information on cerebral oxygen dynamics and sex-related characteristics, as well as considering confounding factors. A study investigating the correlation between changes in fMRI and NIRS during brain activity reported a strong correlation with $\mathrm{O}_{2} \mathrm{Hb}$ but no correlation with $\mathrm{HHb}$ [56]. Therefore, it is difficult to say that NIRS alone reflects neural activity in the state where only $\mathrm{HHb}$ shows changes as in the study. The use of functional magnetic resonance (MR) imaging and MR spectroscopy would be useful in this regard.

\section{Conclusions}

This study focused on sex differences in PFC oxygen dynamics during AE in healthy young adults. We identified significant main effects of sex on the $\mathrm{HHb}$ in the left and right PFC during exercise, with levels being significantly higher in men than in women. Considering the absence of a sex effect on $\mathrm{O}_{2} \mathrm{Hb}, \mathrm{MAP}$, and SBF, our findings are indicative of a higher oxygen consumption in the PFC in men than in women during moderateintensity AE.

Author Contributions: Conceptualization, Y.I., R.S., T.U., S.K., S.M., W.Q. and A.T.; methodology, Y.I., R.S., T.U., S.K., S.M., W.Q. and A.T.; software, Y.I.; validation, Y.I., R.S. and T.U.; formal analysis, Y.I., R.S. and T.U.; investigation, Y.I.; resources, Y.I.; data curation, Y.I.; writing-original draft preparation, Y.I.; writing - review and editing, Y.I.; visualization, Y.I.; supervision, A.T.; project administration, A.T.; funding acquisition, A.T. All authors have read and agreed to the published version of the manuscript.

Funding: A part of this research was funded by a Grant-in-Aid for Scientific Research (B) from the JSPS (20H04042, A. T.) and Grant-in-Aid for Scientific Research (A) from Niigata University of Health and Welfare, 2020 (R02B18, A. T.).

Institutional Review Board Statement: This study was approved by the ethics committee of Niigata University of Health and Welfare (approval number: 17770-170106) and was conducted in accordance with the tenets of the Declaratastion of Helsinki. (January 2017).

Informed Consent Statement: The experimental process has been explained in detail to all participants and informed consent has been obtained.

Data Availability Statement: Not applicable.

Conflicts of Interest: The authors declare no conflict of interest.

\section{References}

1. Bähr, R.; Høstmark, A.T.; Newsholme, E.A.; Grønnerød, O.; Sejersted, O.M. Effect of exercise on recovery changes in plasma levels of FFA, glycerol, glucose and catecholamines. Acta Physiol. Scand. 1991, 143, 105-115. [CrossRef]

2. Al Saif, A.; Alsenany, S. Aerobic and anaerobic exercise training in obese adults. J. Phys. Ther. Sci. 2015, 27, 1697-1700. [CrossRef]

3. Jakicic, J.; Davis, K. Obesity and physical activity. Psychiatr. Clin. N. Am. 2011, 34, 829-840. [CrossRef] [PubMed]

4. Bennie, J.A.; De Cocker, K.; Pavey, T.; Stamatakis, E.; Biddle, S.J.H.; Ding, D. Muscle strengthening, aerobic exercise, and obesity: A pooled analysis of 1.7 million US adults. Obesity 2020, 28, 371-378. [CrossRef] [PubMed]

5. Ohsugi, H.; Ohgi, S.; Kodama, T. Physical activity affects cognitive function in view of prefrontal cortex activation. J. Allied Health Sci. 2014, 5, 69-77. [CrossRef] 
6. León-Carrion, J.; Damas-López, J.; Martín-Rodríguez, J.F.; Domínguez-Roldán, J.M.; Murillo-Cabezas, F.; Martin, J.M.B.Y.; Domínguez-Morales, M.R. The hemodynamics of cognitive control: The level of concentration of oxygenated hemoglobin in the superior prefrontal cortex varies as a function of performance in a modified Stroop task. Behav. Brain Res. 2008, 193, 248-256. [CrossRef] [PubMed]

7. Hashimoto, N.; Yokogawa, M.; Kojima, H.; Tanaka, S.; Nakagawa, T. Effect of moderate exercise intensities on the cortical activity in young adults. J. Phys. Ther. Sci. 2018, 30, 1257-1261. [CrossRef]

8. Giles, G.E.; Brunyé, T.T.; Eddy, M.D.; Mahoney, C.R.; Gagnon, S.A.; Taylor, H.A.; Kanarek, R.B. Acute exercise increases oxygenated and deoxygenated hemoglobin in the prefrontal cortex. Neuroreport 2014, 25, 1320-1325. [CrossRef]

9. Northey, J.M.; Cherbuin, N.; Pumpa, K.L.; Smee, D.J.; Rattray, B. Exercise interventions for cognitive function in adults older than 50: A systematic review with meta-analysis. Br. J. Sports Med. 2017, 52, 154-160. [CrossRef]

10. Falck, R.S.; Davis, J.C.; Best, J.R.; Crockett, R.A.; Liu-Ambrose, T. Impact of exercise training on physical and cognitive function among older adults: A systematic review and meta-analysis. Neurobiol. Aging 2019, 79, 119-130. [CrossRef]

11. El-Sayes, J.; Turco, C.V.; Skelly, L.E.; Nicolini, C.; Fahnestock, M.; Gibala, M.J.; Nelson, A.J. The Effects of Biological Sex and Ovarian Hormones on Exercise-Induced Neuroplasticity. Neuroscience 2019, 410, 29-40. [CrossRef]

12. Hagmar, M.; Berglund, B.; Brismar, K.; Hirschberg, A.L. Body Composition and Endocrine Profile of Male Olympic Athletes Striving for Leanness. Clin. J. Sport Med. 2013, 23, 197-201. [CrossRef] [PubMed]

13. Di Luigi, L.; Romanelli, F.; Sgrò, P.; Lenzi, A. Andrological aspects of physical exercise and sport medicine. Endocrine 2012, 42, 278-284. [CrossRef] [PubMed]

14. Bhasin, S.; Woodhouse, L.; Casaburi, R.; Singh, A.B.; Bhasin, D.; Berman, N.; Chen, X.; Yarasheski, K.E.; Magliano, L.; Dzekov, C.; et al. Testosterone dose-response relationships in healthy young men. Am. J. Physiol. Endocrinol. Metab. 2001, 281, E1172-E1181. [CrossRef] [PubMed]

15. Sinha-Hikim, I.; Cornford, M.; Gaytan, H.; Lee, M.L.; Bhasin, S. Effects of testosterone supplementation on skeletal muscle fiber hypertrophy and satellite cells in community-dwelling older men. J. Clin. Endocrinol. Metab. 2006, 91, 3024-3033. [CrossRef] [PubMed]

16. Rogerson, S.; Weatherby, R.P.; Deakin, G.B.; Meir, R.A.; Coutts, R.A.; Zhou, S.; Marchall-Gradisnik, M. The effect of short-term use of testosterone enanthate on muscular strength and power in healthy young men. J. Strength Cond. Res. 2007, 21, 354-361.

17. Grandys, M.; Majerczak, J.; Duda, K.; Zapart-Bukowska, J.; Kulpa, J.; Zoladz, J. Endurance Training of Moderate Intensity Increases Testosterone Concentration in Young, Healthy Men. Int. J. Sports Med. 2009, 30, 489-495. [CrossRef]

18. Fitzgerald, L.Z.; Robbins, W.A.; Kesner, J.S.; Xun, L. Reproductive hormones and interleukin-6 in serious leisure male athletes Eur. J. Appl. Physiol. 2012, 112, 3765-3773. [CrossRef]

19. Ding, E.L.; Song, Y.; Malik, V.S.; Liu, S. Sex Differences of Endogenous Sex Hormones and Risk of Type 2 Diabetes. JAMA 2006, 295, 1288-1299. [CrossRef]

20. Hak, A.E.; Witteman, J.C.M.; De Jong, F.H.; Geerlings, M.I.; Hofman, A.; Pols, H.A.P. Low Levels of Endogenous Androgens Increase the Risk of Atherosclerosis in Elderly Men: The Rotterdam Study. J. Clin. Endocrinol. Metab. 2002, 87, 3632-3639. [CrossRef]

21. Rosano, G.M.C.; Sheiban, I.; Massaro, R.; Pagnotta, P.; Marazzi, G.; Vitale, C.; Mercuro, G.; Volterrani, M.; Aversa, A.; Fini, M. Low testosterone levels are associated with coronary artery disease in male patients with angina. Int. J. Impot. Res. 2006, 19, 176-182. [CrossRef]

22. Ohlsson, C.; Barrett-Connor, E.; Bhasin, S.; Orwoll, E.; Labrie, F.; Karlsson, M.K.; Ljunggren, Ö.; Vandenput, L.; Mellström, D.; Tivesten, A. High serum testosterone is associated with reduced risk of cardiovascular events in elderly men. The MrOS (Osteoporotic Fractures in Men) study in Sweden. J. Am. Coll. Cardiol. 2011, 58, 1674-1681. [CrossRef]

23. Behan, F.P.; Maden-Wilkinson, T.M.; Pain, M.T.G.; Folland, J.P. Sex differences in muscle morphology of the knee flexors and knee extensors. PLoS ONE 2018, 13, e0190903. [CrossRef] [PubMed]

24. Kraemer, R.R.; Heleniak, R.J.; Tryniecki, J.L.; Kraemer, G.R.; Okazaki, N.J.; Castracane, V.D. Follicular and luteal phase hormonal responses to low-volume resistive exercise. Med. Sci. Sports Exerc. 1995, 27, 809-817. [CrossRef]

25. Walberg-Rankin, J.; Franke, W.D.; Gwazdauskas, F.C. Response of beta-endorphin and estradiol to resistance exercise in females during energy balance and energy restriction. Int. J. Sports Med. 1992, 13, 542-547. [CrossRef]

26. Bar, P.; Amelink, G.; Oldenburg, B.; Blankenstein, M. Prevention of exercise-induced muscle membrane damage by oestradiol. Life Sci. 1988, 42, 2677-2681. [CrossRef]

27. Kochanowicz, J.; Krejza, J.; Koroza, O.; Mariak, Z. Influence of estrogens on the impedance of cerebral blood vessels. Neurol. Neurochir. Pol. 2005, 39, 175-180.

28. Robison, L.S.; Gannon, O.J.; Salinero, A.E.; Zuloaga, K.L. Contributions of sex to cerebrovascular function and pathology. Brain Res. 2019, 1710, 43-60. [CrossRef]

29. Acar, M.; Cevrioglu, A.S.; Haktanir, A.; Demirel, R.; Albayrak, R.; Degirmenci, B.; Yucel, A.; Akyol, A.M. Effect of Aerodiol ${ }^{\circledR}$ administration on cerebral blood flow volume in postmenopausal women. Maturitas 2005, 52, 127-133. [CrossRef]

30. Berent-Spillson, A.; Briceno, E.; Pinsky, A.; Simmen, A.; Persad, C.C.; Zubieta, J.-K.; Smith, Y.R. Distinct cognitive effects of estrogen and progesterone in menopausal women. Psychoneuroendocrinology 2015, 59, 25-36. [CrossRef]

31. Coltheart, M.; Hull, E.; Slater, D. Sex differences in imagery and reading. Nature 1975, 253, 438-440. [CrossRef] [PubMed] 
32. Ward, J.L.; Craig, J.C.; Liu, Y.; Vidoni, E.D.; Maletsky, R.; Poole, D.C.; Billinger, S.A. Effect of healthy aging and sex on middle cerebral artery blood velocity dynamics during moderate-intensity exercise. Am. J. Physiol. Circ. Physiol. 2018, 315, H492-H501. [CrossRef] [PubMed]

33. Ashley, J.D.; Shelley, J.H.; Sun, J.; Song, J.; Trent, J.A.; Ambrosio, L.D.; Larson, D.J.; Larson, R.D.; Yabluchanskiy, A.; Kellawan, J.M. Cerebrovascular responses to graded exercise in young healthy males and females. Physiol. Rep. 2020, 8, e14622. [CrossRef] [PubMed]

34. Kameyama, M.; Fukuda, M.; Uehara, T.; Mikuni, M. Sex and age dependencies of cerebral blood volume changes during cognitive activation: A multichannel near-infrared spectroscopy study. NeuroImage 2004, 22, 1715-1721. [CrossRef] [PubMed]

35. Li, T.; Luo, Q.; Gong, H. Gender-specific hemodynamics in prefrontal cortex during a verbal working memory task by nearinfrared spectroscopy. Behav. Brain Res. 2010, 209, 148-153. [CrossRef]

36. Goldstein, J.M.; Jerram, M.; Poldrack, R.; Anagnoson, R.; Breiter, H.C.; Makris, N.; Goodman, J.M.; Tsuang, M.T.; Seidman, L.J. Sex differences in prefrontal cortical brain activity during fMRI of auditory verbal working memory. Neuropsychology 2005, 19, 509-519. [CrossRef]

37. Hoshi, Y. Functional near-infrared spectroscopy: Current status and future prospects. J. Biomed. Opt. 2007, 12, 062106. [CrossRef]

38. Fox, P.T.; Raichle, M.E. Focal physiological uncoupling of cerebral blood flow and oxidative metabolism during somatosensory stimulation in human subjects. Proc. Natl. Acad. Sci. USA 1986, 83, 1140-1144. [CrossRef]

39. Herrmann, M.; Walter, A.; Fallgatter, A.J. Cerebral oxygenation changes in the prefrontal cortex: Effects of age and sex. Neurobiol. Aging 2006, 27, 888-894. [CrossRef]

40. Ji, Z.; Feng, T.; Mei, L.; Li, A.; Zhang, C. Influence of acute combined physical and cognitive exercise on cognitive function: An NIRS study. PeerJ 2019, 7, e7418. [CrossRef]

41. Tsubaki, A.; Takai, H.; Kojima, S.; Miyaguchi, S.; Sugawara, K.; Sato, D.; Tamaki, H.; Onishi, H. Changes in Cortical Oxyhaemoglobin Signal During Low-Intensity Cycle Ergometer Activity: A Near-Infrared Spectroscopy Study. Adv. Exp. Med. Biol. 2016, 876, 79-85. [CrossRef] [PubMed]

42. Myers, J.; Bellin, D. Ramp Exercise Protocols for Clinical and Cardiopulmonary Exercise Testing. Sports Med. 2000, 30, 23-29. [CrossRef]

43. Morishita, S.; Tsubaki, A.; Nashimoto, S.; Fu, J.B.; Onishi, H. Face scale rating of perceived exertion during cardiopulmonary exercise test. BMJ Open Sport Exerc. Med. 2018, 4, e000474. [CrossRef]

44. Thomas, R.; Stephane, P. Prefrontal cortex oxygenation and neuromuscular responses to exhaustive exercise. Eur. J. Appl. Physiol. 2008, 102, 153-163. [CrossRef]

45. Hopker, J.G.; Jobson, S.A.; Pandit, J.J. Controversies in the physiological basis of the 'anaerobic threshold' and their implications for clinical cardiopulmonary exercise testing. Anaesthesia 2011, 66, 111-123. [CrossRef] [PubMed]

46. Sasai, S.; Homae, F.; Watanabe, H.; Taga, G. Frequency-specific functional connectivity in the brain during resting state revealed by NIRS. NeuroImage 2011, 56, 252-257. [CrossRef]

47. Tong, Y.; Frederick, B.D. Time lag dependent multimodal processing of concurrent fMRI and near-infrared spectroscopy (NIRS) data suggests a global circulatory origin for low-frequency oscillation signals in human brain. NeuroImage 2010, 53, 553-564. [CrossRef]

48. Hatakenaka, M.; Miyai, I.; Mihara, M.; Sakoda, S.; Kubota, K. Frontal regions involved in learning of motor skill—A functional NIRS study. NeuroImage 2007, 34, 109-116. [CrossRef]

49. Hada, Y.; Abo, M.; Kaminaga, T.; Mikami, M. Detection of cerebral blood flow changes during repetitive transcranial magnetic stimulation by recording hemoglobin in the brain cortex, just beneath the stimulation coil, with near-infrared spectroscopy. NeuroImage 2006, 32, 1226-1230. [CrossRef]

50. Bae, S.; Lee, Y.; Chang, P. There is No test-retest reliability of brain activation induced by robotic passive hand movement: A functional NIRS study. Brain Behav. 2020, 10. [CrossRef]

51. Maki, A.; Yamashita, Y.; Ito, Y.; Watanabe, E.; Mayanagi, Y.; Koizumi, H. Spatial and temporal analysis of human motor activity using noninvasive NIR topography. Med. Phys. 1995, 22, 1997-2005. [CrossRef] [PubMed]

52. Mihara, M.; Miyai, I.; Hattori, N.; Hatakenaka, M.; Yagura, H.; Kawano, T.; Okibayashi, M.; Danjo, N.; Ishikawa, A.; Inoue, Y.; et al. Neurofeedback Using Real-Time Near-Infrared Spectroscopy Enhances Motor Imagery Related Cortical Activation. PLoS ONE 2012, 7, e32234. [CrossRef]

53. Sato, K.; Ogoh, S.; Hirasawa, A.; Oue, A.; Sadamoto, T. The distribution of blood flow in the carotid and vertebral arteries during dynamic exercise in humans. J. Physiol. 2011, 589, 2847-2856. [CrossRef]

54. Secher, N.H.; Seifert, T.; Van Lieshout, J.J. Cerebral blood flow and metabolism during exercise: Implications for fatigue. J. Appl. Physiol. 2008, 104, 306-314. [CrossRef]

55. Inoue, Y.; Ichinose-Kuwahara, T.; Tanaka, A.; Tanaka, E.; Ueda, H.; Amano, T.; Tochihara, Y.; Kondo, N. Sex differences in effective and ineffective sweating rates during exercise in hot, humid conditions. In Proceedings of the 15th International Conference on Environmental Ergonomics, Queenstown, New Zealand, 11-15 February 2013; pp. 126-129.

56. Strangman, G.; Culver, J.P.; Thompson, J.H.; Boas, D.A. A Quantitative Comparison of Simultaneous BOLD fMRI and NIRS Recordings during Functional Brain Activation. NeuroImage 2002, 17, 719-731. [CrossRef] 